\title{
Conformational Interconversions in [2]Catenanes \\ Containing a Wide Rigid Bis(p-benyzl)methyl Spacer
}

Ronald L. Halterman*, Xingang Pan, David E. Martyn, Jason L. Moore, Andrew T. Long

Department of Chemistry and Biochemistry,

University of Oklahoma, 620 Parrington Oval, Norman, OK 73019

\section{Supplemental information.}

S2. General Experimental details

S3-S5- $\quad{ }^{1} \mathrm{H}$ NMR spectra of BPP34C10 and 5-8

S6-S9 $\quad{ }^{1} \mathrm{H}$ NMR and HSQC spectra of catenanes 1-4

S10-S11 VT NMR spectra of catenane 3. 
General Experimental Data: Chemicals and solvents were purchased from commercial suppliers and used without further purification unless otherwise noted. Preparative thin-layer chromatography (TLC) was performed using either $2 \mathrm{~mm}, 1$ $\mathrm{mm}$ or $0.5 \mathrm{~mm}$ glass-backed sheets pre-coated with silica gel 60 F254.

Column chromatography was carried out using silica gel $60 \mathrm{~F}$ (0.040 to $0.063 \mathrm{~mm}$ particle size). ${ }^{1} \mathbf{H}$ and ${ }^{13} \mathbf{C}$ NMR spectra were recorded on either a 400 or $300 \mathrm{MHz}$ machine using residual solvent as internal standards: $\mathrm{CHCl}_{3}$ at $7.26 \mathrm{ppm}$, or $\mathrm{C}_{3} \mathrm{H}_{6} \mathrm{O}$ at $2.05 \mathrm{ppm} .{ }^{\mathbf{1 3}} \mathbf{C}$ NMR data were collected from HSQC spectra. Chemical shifts are denoted in ppm and coupling constants in Hertz. Abbreviations for NMR spectra are as follows: $\mathrm{s}=$ singlet, $\mathrm{bs}=$ broad singlet, $\mathrm{d}=$ doublet, $\mathrm{t}=$ triplet, $\mathrm{q}=$ quartet, $\mathrm{m}=$ multiplet. $\mathrm{NMR}$ samples were dissolved in $\mathrm{CD}_{3} \mathrm{COCD}_{3}$ or $\mathrm{CDCl}_{3}$. 
RL Halterman

Supplementary Information

Page S3

BPP34C10

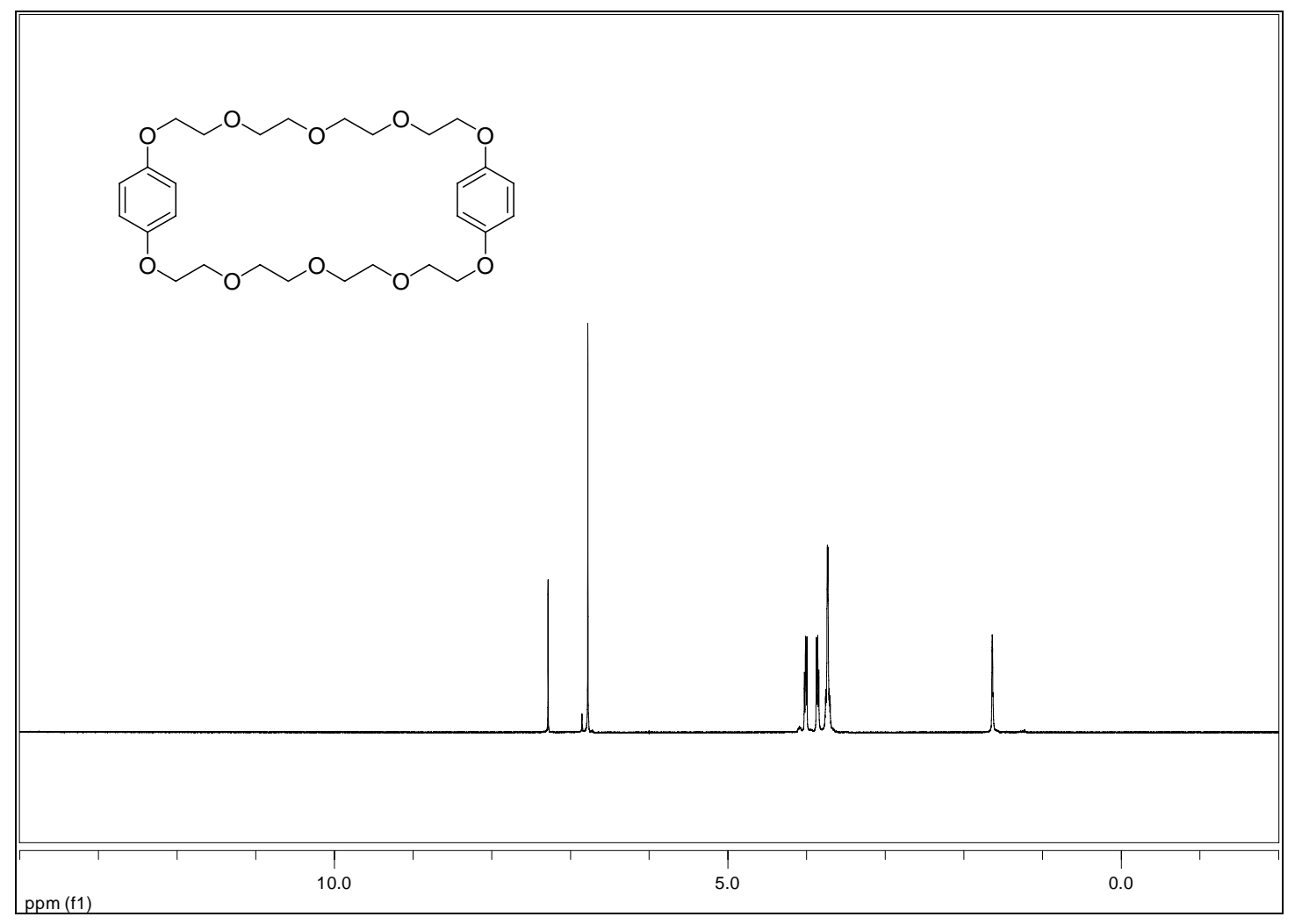

Bis(4-bromomethylphenyl)methane (5).

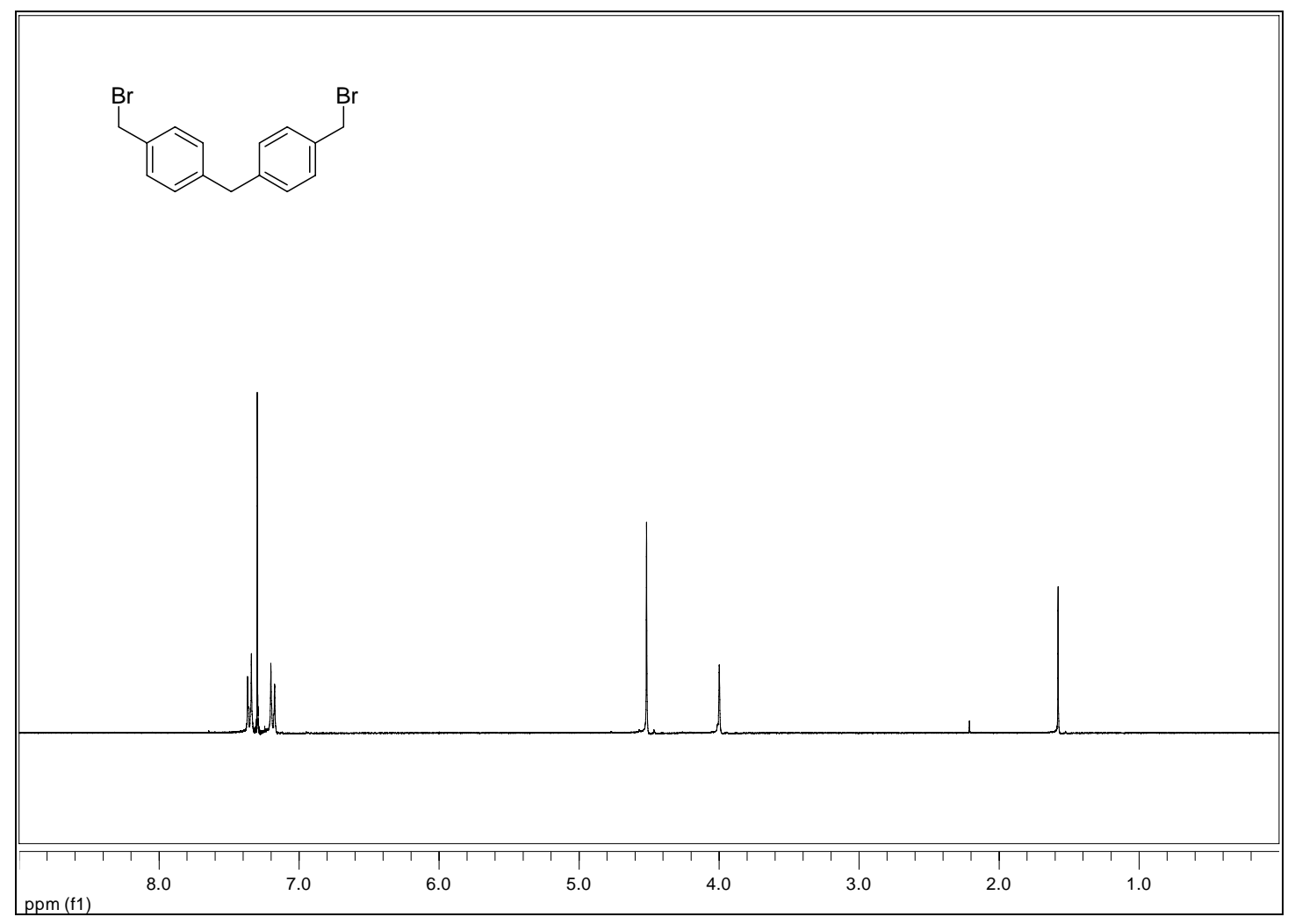


(4-tert-Butyl-phenyl)-di-p-tolyl-methanol (6)

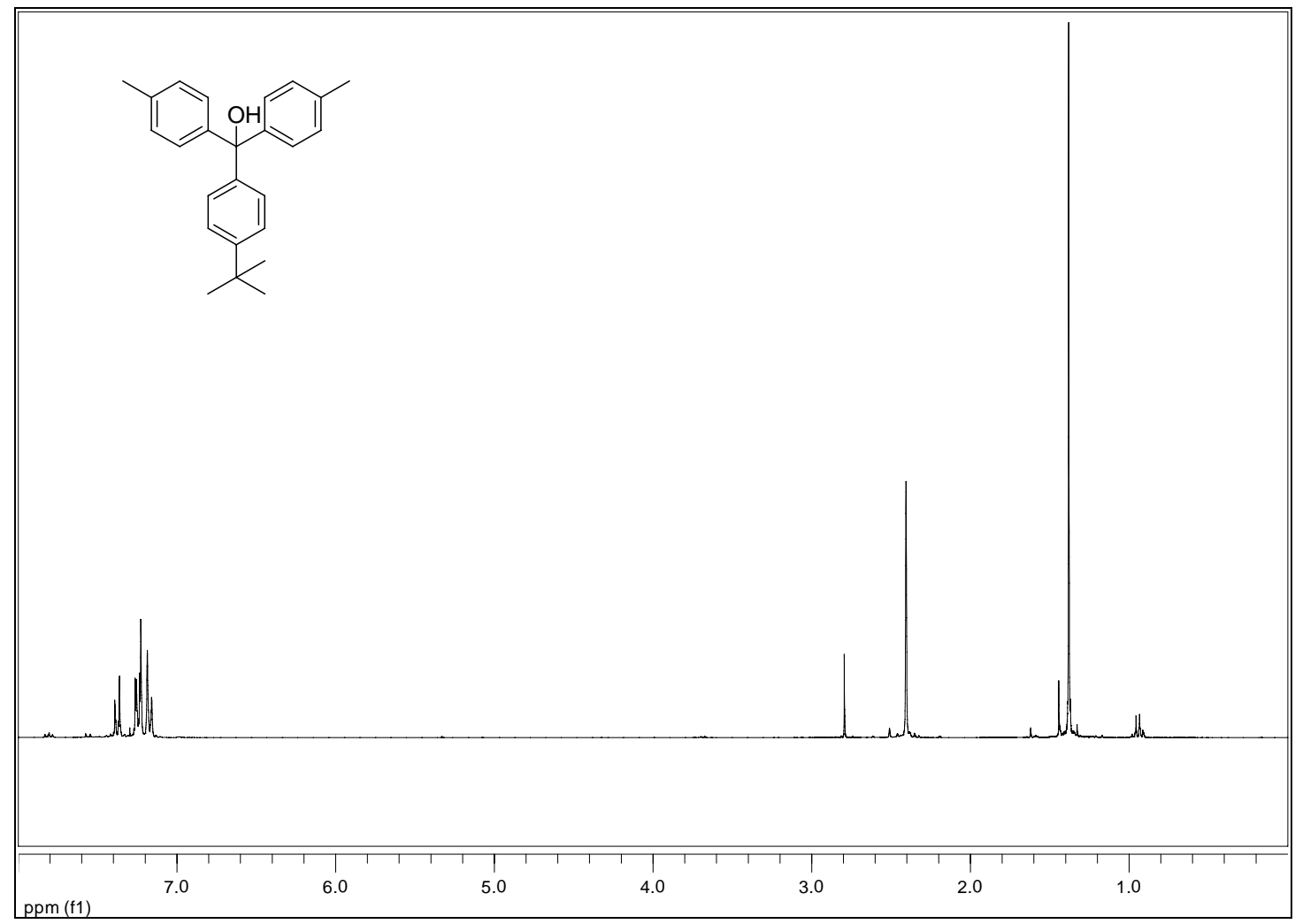

Bis-(4-bromomethyl-phenyl)-(4-tert-butyl-phenyl)-methanol (7).

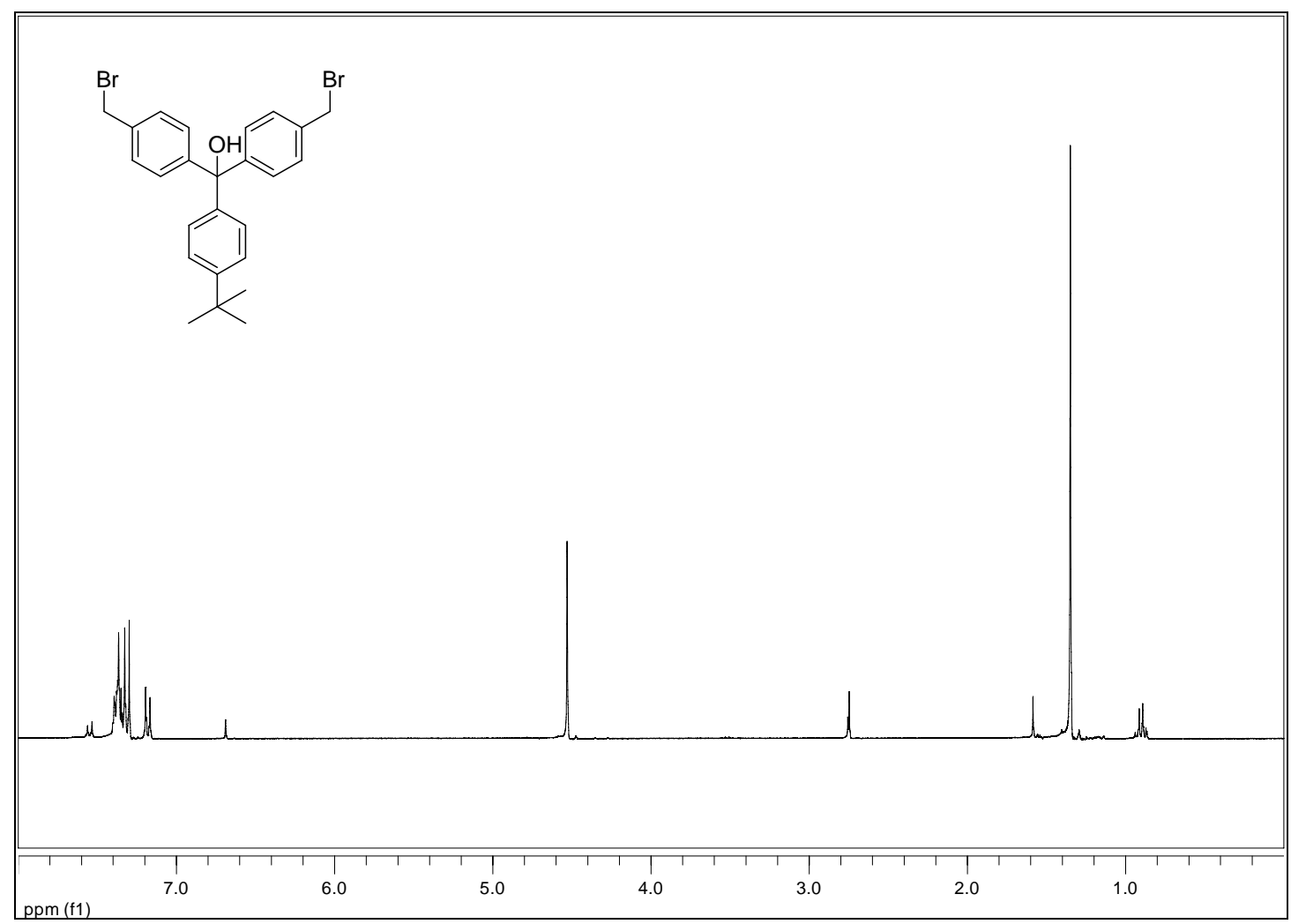


1,1'-[[4-(1,1-dimethylethyl)phenyl]-methylene]bis[4-(bromomethyl)]benzene (8).
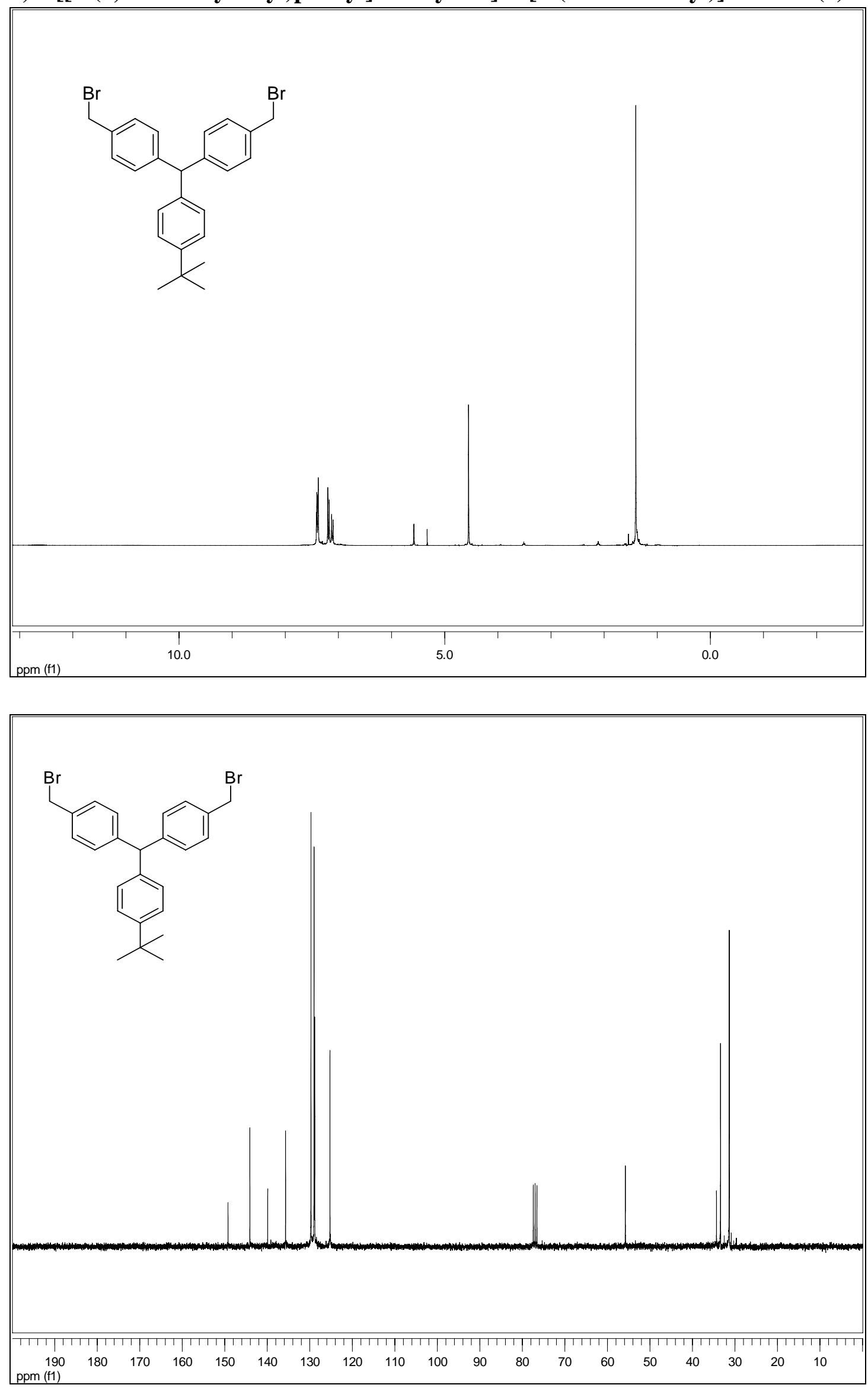


\section{Catenane 1.}
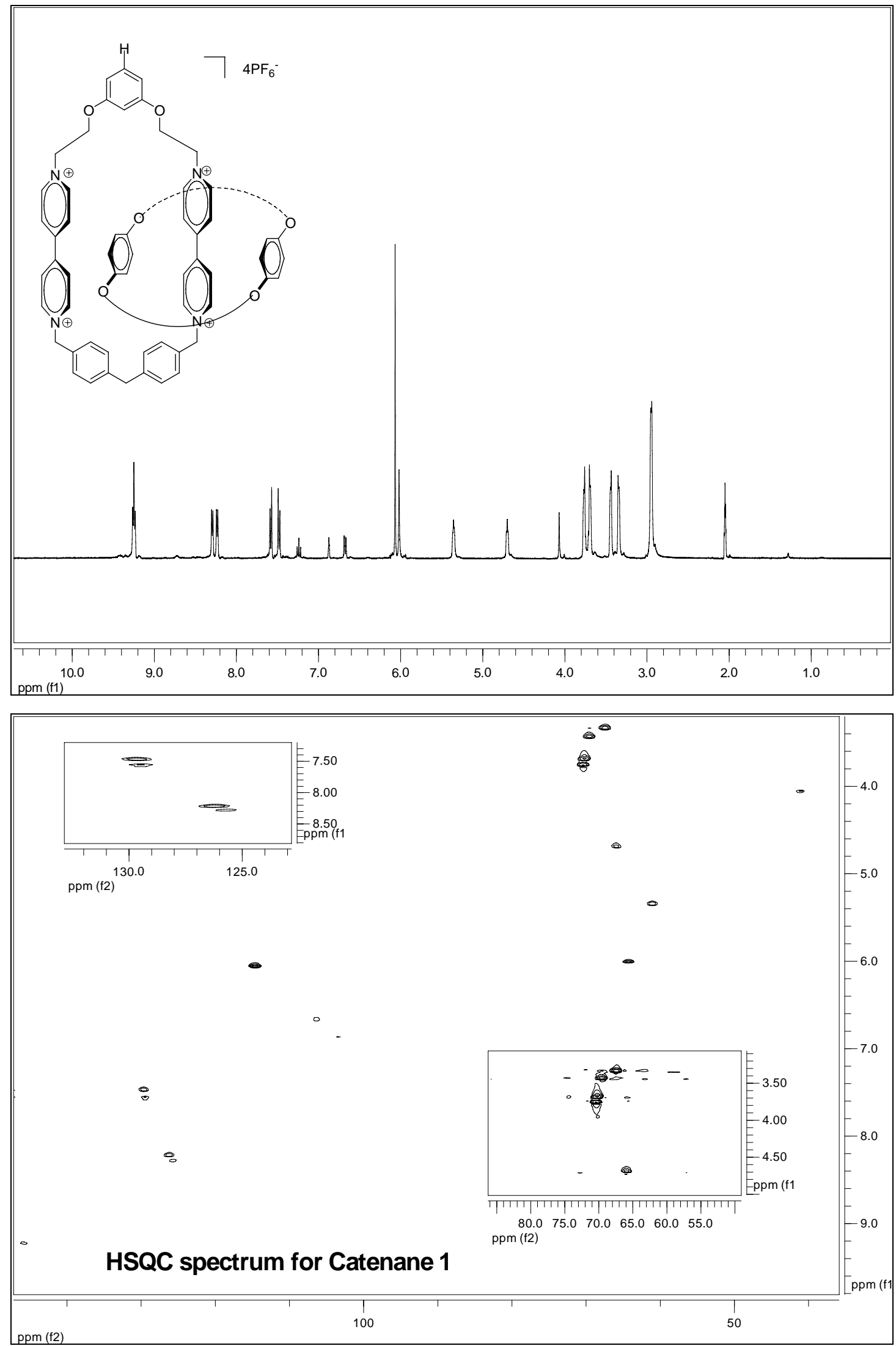


\section{Catenane 2.}
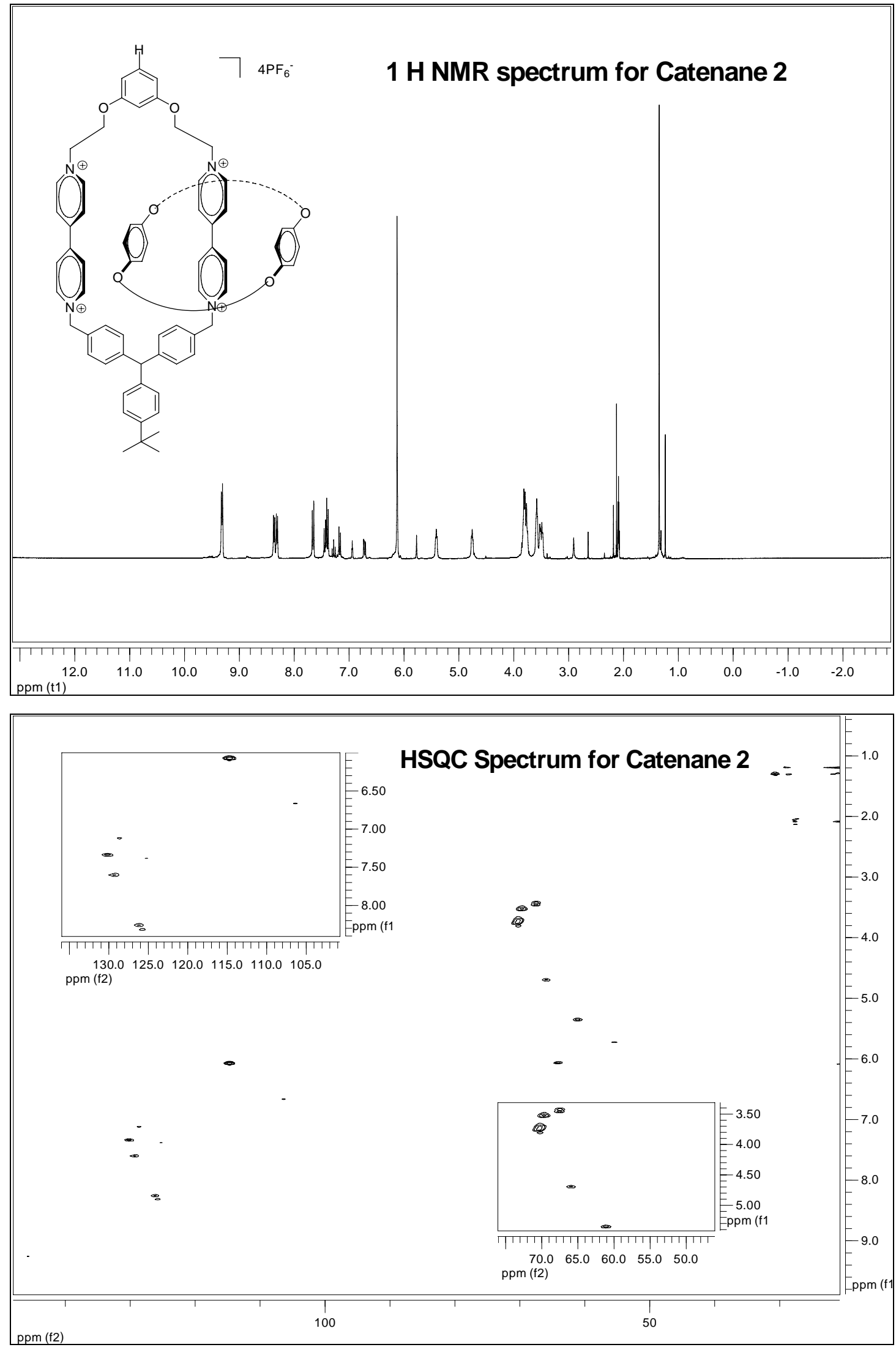


\section{Catenane 3.}
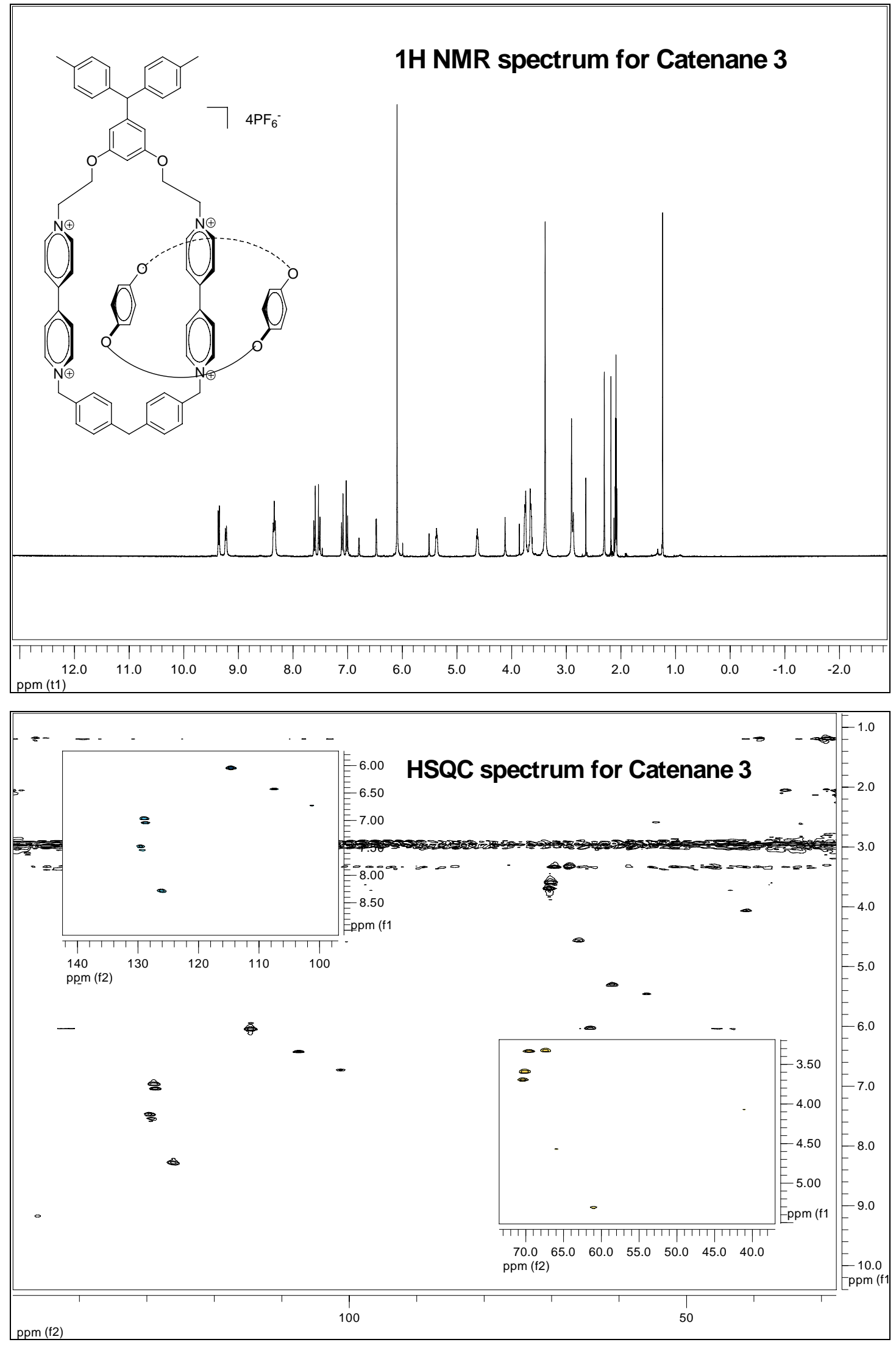


\section{Catenane 4.}
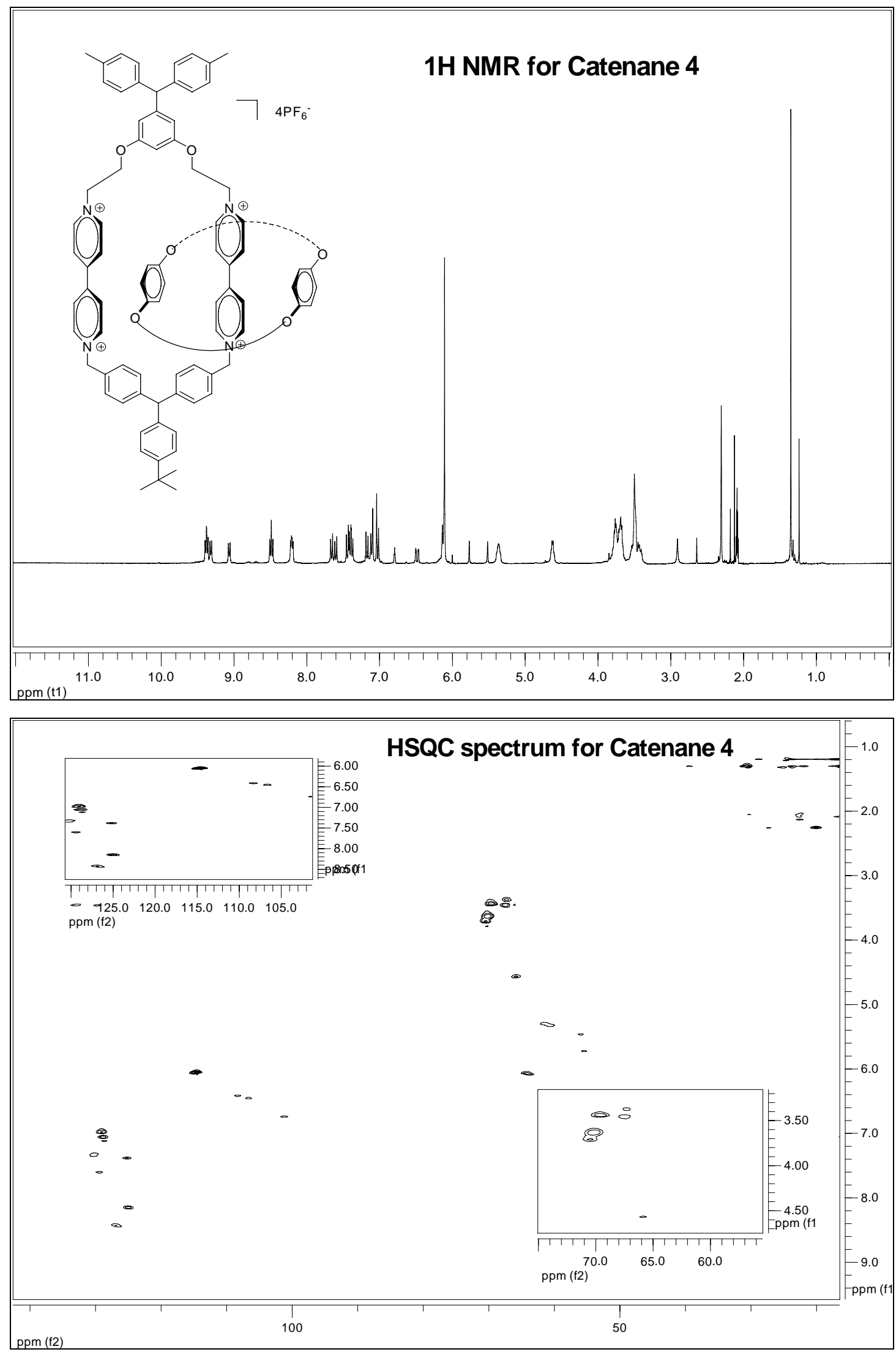
VT ${ }^{1} \mathbf{H}-\mathbf{N M R} 400 \mathrm{MHz}$ Spectra of Catenane 3:

Full spectra at temperatures $+20{ }^{\circ} \mathrm{C}$ and $-60{ }^{\circ} \mathrm{C}$ are provided for reference. The stacked plot (sweep width 9.60 to $8.00 \mathrm{ppm}$ ) of Catenane 3 seen below is typical of the VT ${ }^{1} \mathrm{H}$ NMR spectra observed for the catenanes. For Catenane 3 protons of the dipyridinium rings were observed to coalesce at $-35^{\circ} \mathrm{C}$ (doublet $\mathrm{A}$ and doublet $\mathrm{B}$ ).
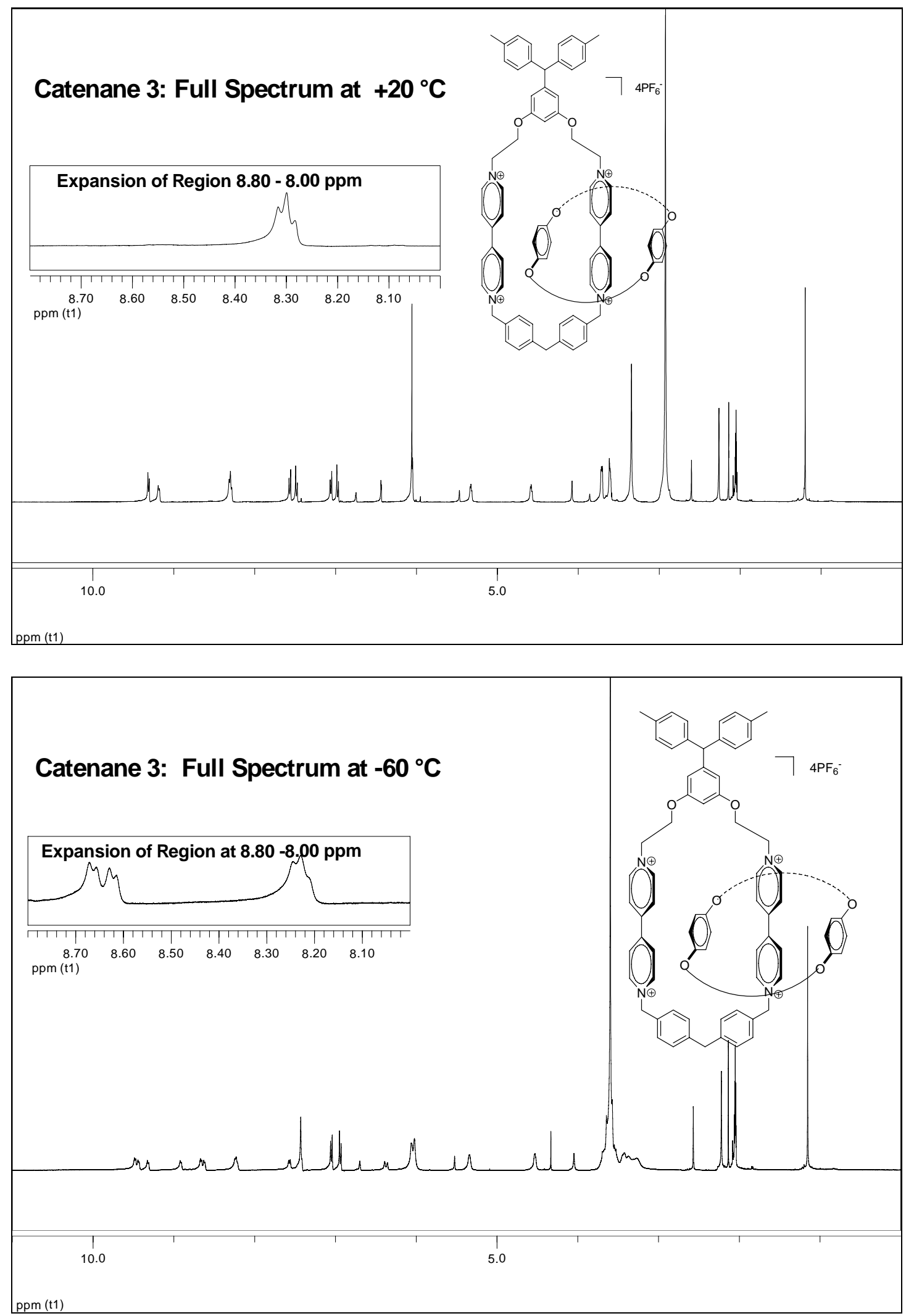
Catenane 3: Stacked plot (9.60 ppm - 8.00 ppm)

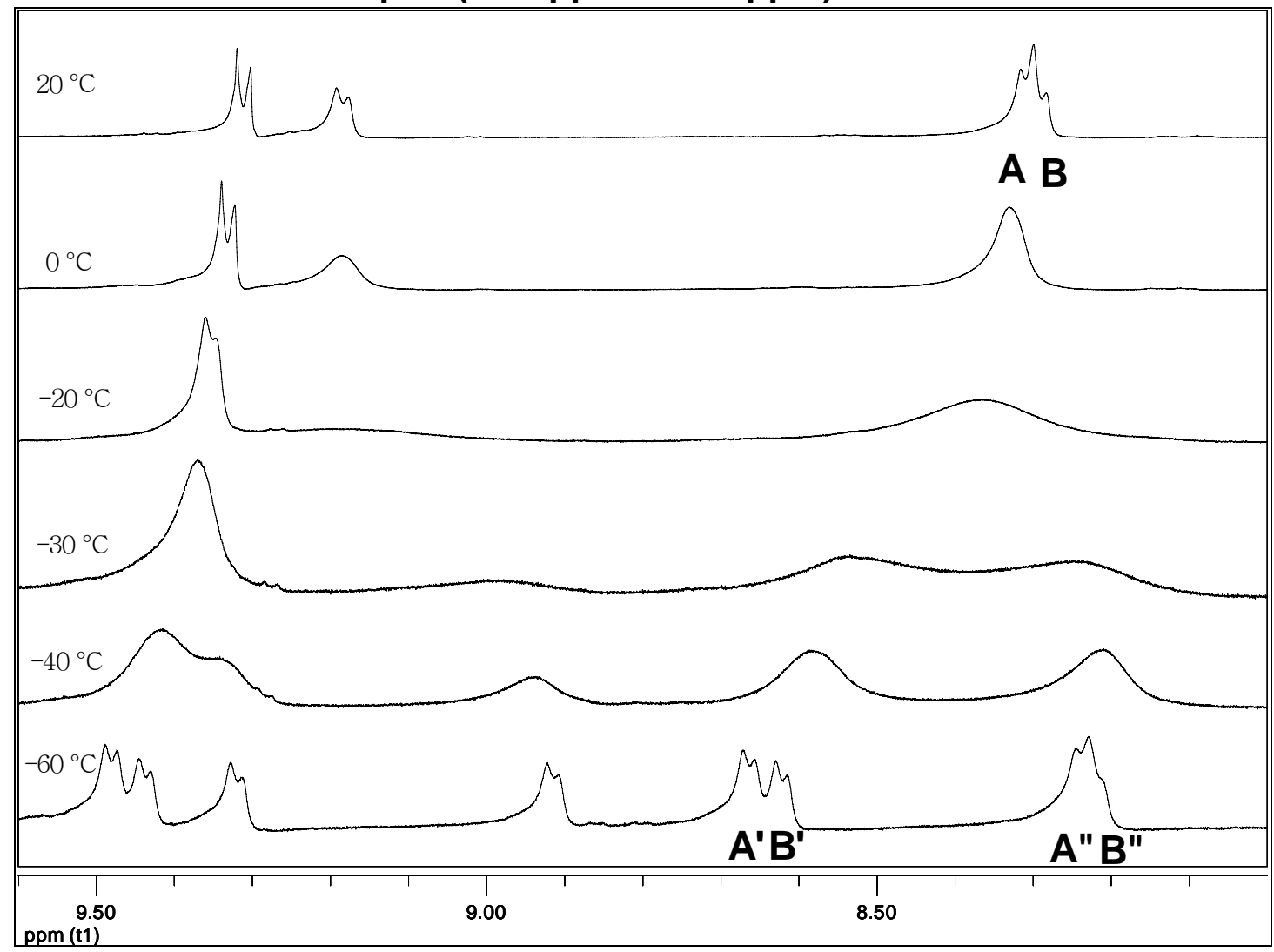

